\title{
Metformin and aspirin treatment could lead to an improved survival rate for Type 2 diabetic patients with stage II and III colorectal adenocarcinoma relative to non-diabetic patients
}

\author{
ARIELLA DE MONTE $^{1 *}$, DAVIDE BRUNETTI ${ }^{2 *}$, LUIGI CATTIN $^{2}$, FRANCESCA LAVANDA $^{2}$, \\ ERICA NAIBO $^{2}$, MARIA MALAGOLI ${ }^{3}$, GIORGIO STANTA ${ }^{2}$ and SERENA BONIN $^{2}$ \\ ${ }^{1}$ Unit of Medical Clinic, University Hospital of Cattinara-ASUITS; ${ }^{2}$ Department of Medical Sciences, \\ University of Trieste, Cattinara Hospital; ${ }^{3}$ Oncology Unit, University Hospital of Cattinara-ASUITS, I-34149 Trieste, Italy
}

Received August 19,2017; Accepted November 30, 2017

DOI: $10.3892 / \operatorname{mco} .2018 .1554$

\begin{abstract}
Metformin, the drug of choice in the treatment of type 2 diabetes mellitus (DM2), in addition to aspirin (ASA), the drug prescribed for cardioprotection of diabetic and non-diabetic patients, have an inhibitory effect on cancer cell survival. The present population-based study conducted in the province of Trieste (Italy), aimed to investigate the prevalence of DM2 in patients with colorectal adenocarcinoma (CRC) and survival for CRC in diabetic and nondiabetic patients. All permanent residents diagnosed with a CRC between 2004 and 2007 were ascertained through the regional health information system. CRC-specific and relative survival probabilities were computed for each group of patients defined by CRC stage, presence or absence of DM2 treated with metformin, and presence or absence of daily ASA therapy. A total of 515 CRC patients without DM2 and 156 with DM2 treated with metformin were enrolled in the study. At the time of CRC diagnosis, $71(14 \%)$ nondiabetic and $39(25 \%)$ diabetic patients were taking ASA daily. The five-year relative survival for stage III CRC was $101 \%$ [95\% confidence interval $(\mathrm{CI})=76-126]$ in the 18 patients with DM2 treated with metformin and ASA, $55 \%$ (95\% CI=31-78) in the 23 without DM2 treated with ASA, $55 \%$ (95\% CI=45-65) in the 150 without DM2 not taking ASA, and $29 \%(95 \% \mathrm{CI}=13-45)$ in the 43 with DM2 treated with metformin, however not with ASA. The findings support the hypothesis of a possible inhibitory effect of metformin and ASA on CRC cells. Randomized controlled trials are required to verify this hypothesis.
\end{abstract}

Correspondence to: Dr Serena Bonin, Department of Medical Sciences, University of Trieste, Cattinara Hospital, Strada di Fiume 447, I-34149 Trieste, Italy

E-mail:sbonin@units.it

${ }^{*}$ Contributed equally

Key words: colorectal cancer, type 2 diabetes mellitus, metformin, aspirin, survival

\section{Introduction}

Diabetes mellitus and colorectal adenocarcinoma (CRC) are common diseases worldwide $(1,2)$. There is considerable evidence that people with type 2 diabetes mellitus (DM2) have an increased risk of developing several cancer types, among them CRC. Meta-analysis results indicate that diabetic patients have a 1.3 -fold risk of developing CRC as well as a 1.3 -fold risk of dying from it if compared to the general population and to cancer patients without diabetes, respectively $(3,4)$.

Chronic hyperinsulinemia may increase the risk of cancer because of the mitogenic and antiapoptotic effect of insulin. Glucose-lowering therapies have been implicated in modulating cancer risk in DM2 patients with controversial results (4). Diabetes medications such as insulin or secretagogues, which increase circulating insulin levels, have been reported to increase cancer risk (5). Conversely, insulin sensitizers such as metformin, the drug of choice in the DM2 treatment, seem to reduce cancer risk by decreasing hyperinsulinemia (5). Metformin as well as acetylsalicylic acid (ASA, aspirin), a drug prescribed for cardioprotection of patients with or without DM2, also inhibit the mTOR signalling pathway, which is commonly mutated and constitutively active in many adenocarcinomas (6). Moreover, a synergistic or additive inhibitory effect of metformin with ASA on lung and prostate cancer cell survival due to depletion of de novo lipogenesis was found by $\mathrm{O}$ 'Brien at al (7).

This population-based study was aimed at investigating prevalence of DM2 among CRC patients and survival for CRC in patients with and without DM2.

\section{Patients and methods}

The present study was approved by the Ethics Committee of the University of Trieste (Report number 37, 10/02/2012) and was conducted in accordance with the Declaration of Helsinki protocols. Furthermore, clinical data were available only for patients who signed an informed consent for research use of their data.

All permanent residents of the northeastern Italian province of Trieste (2013 population, 232,000) histologically diagnosed with a first primary invasive adenocarcinoma of the colon 
(excluding appendix) or of the rectum between January 1, 2004 and December 31, 2007 were ascertained through the regional health information system. Cases discovered at autopsy were excluded from the analyses.

Medical records, pathology reports and the regional health information system were examined for information on patients (date of birth, sex, date of last follow-up or death, underlying and contributing causes of death); on CRC (date and basis of diagnosis, primary site, histological type, stage according to the 7th TNM classification (8), type and place of treatments, local recurrence); on DM2 diagnosed according to the criteria of the American Diabetes Association (9) and on any other chronic disease (type, date and basis of diagnosis, treatments). All diabetic patients had been diagnosed with the disease at least one year before CRC detection, but we were not able to precisely quantify the duration of DM2 or of treatment with antidiabetic drugs and ASA in the majority of patients because their medical records were incomplete.

Patients were followed-up from the date of CRC diagnosis to death or December 31, 2013, whichever was the earliest. None was lost to follow-up. Underlying and contributing causes of death classified according to the International Statistical Classification of Diseases, 10th revision (10) were known for all deceased individuals.

Proportions were compared through Fisher exact test (11). One-way analysis of variance followed by Scheffé test (11) were used to examine the significance of the differences between the mean values of plasma parameters for the four groups in which participants were allocated according to presence or absence of DM2 treated with metformin, and presence or absence of daily ASA therapy.

Two parametric regression survival-time models, i.e. Gompertz and log-logistic models (12), and Cox proportional-hazards regression model (12) were used to analyse possible factors affecting mortality from CRC. The test proposed by Grambsch and Therneau (13) was used to evaluate the assumption that hazard ratios in Cox analysis were proportional over time.

CRC-specific survival probabilities were computed by the actuarial method (14) for each group of patients defined by CRC stage, DM2 status, and metformin and ASA use, and were compared with the logrank test (12). Relative survival probability (14) of each group of patients was calculated using the procedure described by Ederer et al (15). Data on the number of survivors in the province of Trieste between 2004 and 2015 by sex and 5 -year age groups were provided by the National Institute for Statistics (16). Cornfield's formulas (17) were applied to estimate the limits of the $95 \%$ CI of the ratio of two relative survivals. Chi-square test for heterogeneity (17) was used to compare relative survival of different patient groups.

For each group of patients, Cox survival curves adjusted for sex and age at CRC diagnosis were compared with the likelihood ratio test (12).

Statistical analyses were performed using Stata/SE 12 (StataCorp, College Station, TX, USA).

\section{Results}

Between 2004 and 2007 in the province of Trieste a first primary invasive CRC was diagnosed histologically in

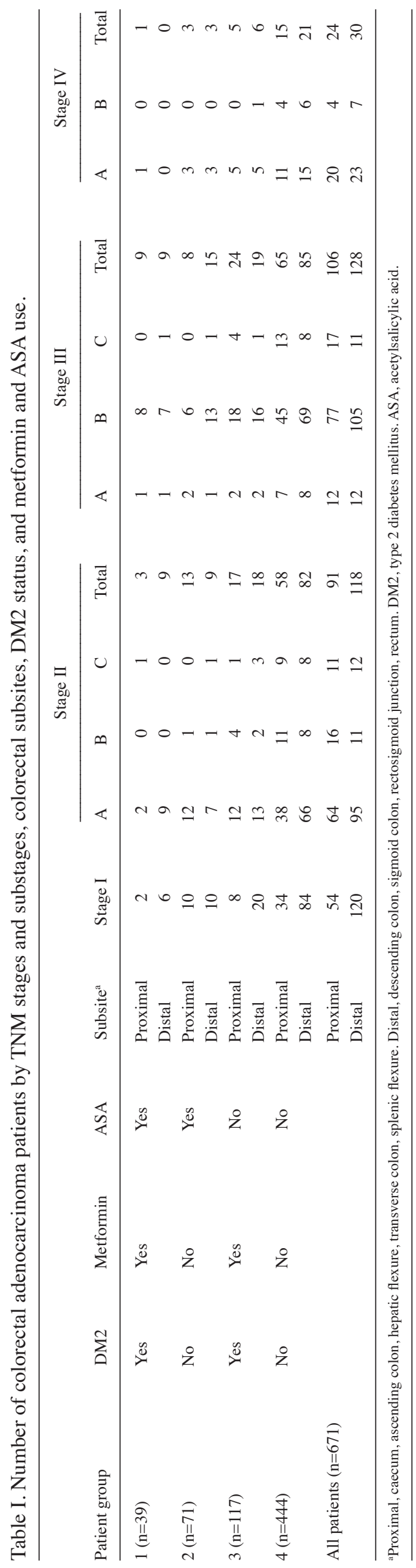


Table II. Number of patients with local recurrence of colorectal cancer by TNM stages, DM2, and metformin and ASA use.

\begin{tabular}{|c|c|c|c|c|c|c|c|c|}
\hline Patient group & DM2 & Metformin & ASA & Number of patients & Stage I & Stage II & Stage III & Stage IV \\
\hline \multirow[t]{3}{*}{1} & \multirow[t]{3}{*}{ Yes } & \multirow[t]{3}{*}{ Yes } & \multirow[t]{3}{*}{ Yes } & Total & 8 & 12 & 18 & 1 \\
\hline & & & & With local recurrence & 1 & 1 & 0 & 0 \\
\hline & & & & $\%$ & 13 & 8 & 0 & 0 \\
\hline \multirow[t]{3}{*}{2} & \multirow[t]{3}{*}{ No } & \multirow[t]{3}{*}{ No } & \multirow[t]{3}{*}{ Yes } & Total & 20 & 22 & 23 & 6 \\
\hline & & & & With local recurrence & 2 & 0 & 2 & 0 \\
\hline & & & & $\%$ & 10 & 0 & 9 & 0 \\
\hline \multirow[t]{3}{*}{3} & \multirow[t]{3}{*}{ Yes } & \multirow[t]{3}{*}{ Yes } & \multirow[t]{3}{*}{ No } & Total & 28 & 35 & 43 & 11 \\
\hline & & & & With local recurrence & 3 & 1 & 5 & 0 \\
\hline & & & & $\%$ & 11 & 3 & 12 & 0 \\
\hline \multirow[t]{3}{*}{4} & \multirow[t]{3}{*}{ No } & \multirow[t]{3}{*}{ No } & \multirow[t]{3}{*}{ No } & Total & 118 & 140 & 150 & 36 \\
\hline & & & & With local recurrence & 7 & 18 & 20 & 2 \\
\hline & & & & $\%$ & 6 & 13 & 13 & 6 \\
\hline \multirow[t]{3}{*}{ All patients } & & & & Total & 174 & 209 & 234 & 54 \\
\hline & & & & With local recurrence & 13 & 20 & 27 & 2 \\
\hline & & & & $\%$ & 7 & 10 & 12 & 4 \\
\hline
\end{tabular}

DM2, type 2 diabetes mellitus; ASA, acetylsalicylic acid.

690 individuals, 175 of whom were identified as having DM2. At the time of CRC diagnosis, 156 DM2 patients had been under treatment with metformin (105 with metformin only and 51 in association with sulphonylureas, meglitinides or incretin mimetics), 6 with insulin, 4 with meglitinides, 3 with sulphonylureas and 6 with diet alone.

The present study enrolled the 515 CRC patients without DM2 (282 males and 233 females) and the 156 with DM2 treated with metformin (102 males and 54 females). The proportion of males and females in these two groups differed significantly $(\mathrm{P}=0.02)$.

At the time of CRC diagnosis, 71 (14\%) patients without DM2 and 39 (25\%) with DM2 were taking ASA daily. The proportion of patients taking ASA differed significantly between diabetics and non-diabetics $(\mathrm{P}=0.002)$.

The 39 patients ( 27 males and 12 females) with DM2 and treated with metformin and ASA (Group 1), and the 71 patients (44 males and the 27 females) without DM2 and treated with ASA (Group 2) showed a median age at CRC diagnosis of 77 years (Group 1: 25th-75th percentile=71-83; Group 2: 25th-75th percentile $=69-82$ ). The median age at diagnosis among the 117 patients ( 75 males and the 42 females) with DM 2 treated with metformin but not with ASA (Group 3) was 73 years (25th-75th percentile $=67-78)$, and it was $71(25$ th-75th percentile $=63-78)$ in the 444 patients (238 males and 206 females) without DM2 and not taking ASA (Group 4). The non-parametric test for trend (18) showed that age at CRC diagnosis tended to decrease significantly across the four patient groups $(\mathrm{P}<0.0001)$.

Of the 671 adenocarcinomas 654 were not otherwise specified, 8 mucinous, 6 in adenomatous polyp and 3 in tubulovillous adenoma. No adenocarcinomas in adenomatous polyps and/or in tubulovillous adenoma were found in the patients belonging to the previously described Groups 1 and 2, and no mucinous ones were diagnosed in Group 4 patients. However, the distribution of the histological types among the four groups of patients did not differ statistically.

A total of 221 adenocarcinomas (33\%) were within the left-sided colon: 133 in the sigmoid colon, 70 in the descending colon and 18 in the splenic flexure. There were 218 (32\%) right-sided lesions: 133 in the ascending colon, 46 in the caecum and 39 in the hepatic flexure. One hundred and forty-one lesions (21\%) arose in the rectum, $52(8 \%)$ in the rectosigmoid junction and $39(6 \%)$ in the transverse colon.

Distribution of patients by group, colorectal subsite, and TNM stage and substage for CRC is shown in Table I. No statistically significant differences were found among the four groups.

All patients had been treated in the three hospitals of the province of Trieste according to up-to-date therapy protocols. All stage I, II and III cancers had undergone potentially curative treatments.

Local CRC recurrence was experienced by 62 patients (9\%) (Table II): 5, 6, 8 and $11 \%$ among patients belonging to respectively Groups 1, 2, 3 and 4 . The proportion of local recurrences did not differed statistically across the four patient groups.

Table III shows the mean values of four admission plasma parameters. Patients belonging to Group 3 showed a mean value of glucose and triglycerides significatively higher than those belonging to the other three groups and than those belonging to Groups 2 and 4, respectively. Total cholesterol and HDL cholesterol were higher in Group 2 with a statistically significant difference between Groups 2 and 3 for HDL cholesterol.

Of the 515 CRC patients without DM2, 339 (66\%) suffered from 494 chronic diseses other than CRC: 1 chronic disease in 217 patients, 2 in 99, 3 in 15,4 in 6 and 5 in 2 patients. The two most frequent categories of comorbidities were cardiovascular diseases (287 patients, 56\%) and invasive malignant tumours (103 patients, $20 \%$ ). The most frequent malignancy was prostate cancer among males (32 patients) and breast cancer among females (13 patients).

Other than CRC and DM2 229 chronic diseases were detected in 142 out of 156 diabetic patients (91\%): 1 chronic disease in 79 patients, 2 in 43, 3 in 16, and 4 in 4 patients. Cardiovascular disases (135 patients, 87\%) and invasive cancers (38 patients, 24\%) were the two most frequent disease 
Table III. Mean values of admission plasma parameters of the 671 study participants by patient groups.

\begin{tabular}{|c|c|c|c|c|c|c|c|}
\hline \multirow[b]{2}{*}{ Patient group } & \multirow[b]{2}{*}{ DM2 } & \multirow[b]{2}{*}{ Metformin } & \multirow[b]{2}{*}{ ASA } & \multicolumn{4}{|c|}{ Mean value of admission plasma parameter (mg/dl) } \\
\hline & & & & Glucose $^{\mathrm{a}} \mathrm{SD}$ & Triglycerides $^{\mathrm{b}} \mathrm{SD}$ & Total cholesterol SD & $\mathrm{HDL}_{\text {cholesterol }}{ }^{\mathrm{S}} \mathrm{SD}$ \\
\hline \multirow[t]{2}{*}{$1(n=39)$} & \multirow[t]{2}{*}{ Yes } & \multirow[t]{2}{*}{ Yes } & \multirow[t]{2}{*}{ Yes } & 97 & 135 & 185 & 46 \\
\hline & & & & 22 & 62 & 46 & 16 \\
\hline \multirow{2}{*}{$2(\mathrm{n}=71)$} & \multirow[t]{2}{*}{ No } & \multirow[t]{2}{*}{ No } & \multirow[t]{2}{*}{ Yes } & 93 & 106 & 188 & 53 \\
\hline & & & & 12 & 34 & 46 & 18 \\
\hline \multirow[t]{2}{*}{$3(n=117)$} & \multirow[t]{2}{*}{ Yes } & \multirow[t]{2}{*}{ Yes } & \multirow[t]{2}{*}{ No } & 107 & 140 & 185 & 46 \\
\hline & & & & 22 & 84 & 52 & 15 \\
\hline \multirow[t]{2}{*}{$4(n=444)$} & \multirow[t]{2}{*}{ No } & \multirow[t]{2}{*}{ No } & \multirow[t]{2}{*}{ No } & 94 & 113 & 187 & 50 \\
\hline & & & & 13 & 54 & 60 & 16 \\
\hline
\end{tabular}

${ }^{\mathrm{a}}$ Group 1 vs. group 3: $\mathrm{P}=0.01$. Group 2 vs. group 3: $\mathrm{P}<0.0001$. Group 3 vs. group 4 : $\mathrm{P}<0.0001$. ${ }^{\mathrm{b}} \mathrm{Group} 2$ vs. group 3: $\mathrm{P}=0.003$. Group 3 vs. group 4: $\mathrm{P}<0.0001$. ${ }^{\mathrm{C}} \mathrm{Group} 2$ vs. group 3 : $\mathrm{P}=0.02$. DM2, type 2 diabetes mellitus; ASA, acetylsalicylic acid; SD, standard deviation.

Table IV. Chronic diseases other than colorectal cancer and DM2 diagnosed in the 671 study participants by patient groups.

\begin{tabular}{|c|c|c|c|c|c|}
\hline \multirow[b]{2}{*}{ Disease category $(\mathrm{ICD}-10 \text { codes })^{\mathrm{b}}$} & & \multicolumn{4}{|c|}{ Patient group ${ }^{a}$} \\
\hline & & $1(\mathrm{n}=39)$ & $2(n=71)$ & $3(\mathrm{n}=117)$ & $4(n=444)$ \\
\hline \multirow[t]{2}{*}{ Invasive malignant neoplasms $(\mathrm{C} 00-\mathrm{C} 17, \mathrm{C} 18.1, \mathrm{C} 21-\mathrm{C} 96)$} & Number & 9 & 19 & 29 & 84 \\
\hline & $\%$ & 23 & 27 & 25 & 19 \\
\hline \multirow[t]{2}{*}{ Diseases of the blood and disorders involving the immune mechanism (D50-D89) } & Number & 1 & 1 & 1 & 6 \\
\hline & $\%$ & 3 & 1 & 1 & 1 \\
\hline \multirow[t]{2}{*}{ Endocrine, nutritional and metabolic diseases (E00-E10, E15-E90) } & Number & 2 & 3 & 7 & 12 \\
\hline & $\%$ & 5 & 4 & 6 & 3 \\
\hline \multirow{2}{*}{ Mental and behavioural disorders (F00-F99) } & Number & 0 & 3 & 3 & 7 \\
\hline & $\%$ & 0 & 4 & 3 & 2 \\
\hline \multirow[t]{2}{*}{ Diseases of the nervous system (G00-99) } & Number & 0 & 0 & 2 & 6 \\
\hline & $\%$ & 0 & 0 & 2 & 1 \\
\hline \multirow[t]{2}{*}{ Diseases of the circulatory system (I00-I99) ${ }^{c}$} & Number & 32 & 37 & 103 & 250 \\
\hline & $\%$ & 82 & 52 & 88 & 56 \\
\hline \multirow[t]{2}{*}{ Diseases of the respiratory system (J00-J99) $)^{\mathrm{d}}$} & Number & 8 & 5 & 6 & 23 \\
\hline & $\%$ & 21 & 7 & 5 & 5 \\
\hline \multirow[t]{2}{*}{ Diseases of the digestive system (K00-K99) } & Number & 0 & 2 & 4 & 12 \\
\hline & $\%$ & 0 & 3 & 3 & 3 \\
\hline \multirow[t]{2}{*}{ Diseases of the musculoskeletal system and connective tissue (M00-M99) } & Number & 0 & 1 & 1 & 3 \\
\hline & $\%$ & 0 & 1 & 1 & 1 \\
\hline \multirow[t]{2}{*}{ Diseases of the genitourinary system $(\mathrm{N} 00-\mathrm{N} 99)^{e}$} & Number & 7 & 7 & 14 & 13 \\
\hline & $\%$ & 18 & 10 & 12 & 3 \\
\hline
\end{tabular}

aDM2: Yes, metformin: Yes, ASA: Yes. Group 2: DM2: No, metformin: No, ASA: Yes. Group 3: DM2: Yes, metformin: Yes, ASA: No. Group 4: DM2: No, metformin: No, ASA:

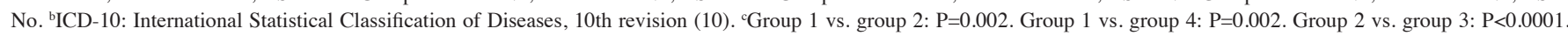
Group 3 vs. group 4: $\mathrm{P}<0.0001$. ${ }^{\mathrm{d}}$ Group 1 vs. group 3: $\mathrm{p}=0.007$. Group 1 vs. group 4: $\mathrm{P}=0.002$. ${ }^{\mathrm{e}}$ Group 1 vs. group 4: $\mathrm{P}<0.0001$. Group 2 vs. group 4: $\mathrm{P}=0.01$. Group 3 vs. group 4: $\mathrm{P}<0.0001$. DM2, diabetes mellitus; ASA, acetylsalicylic acid.

categories. Prostate cancer (8 patients) and breast cancer (5 patients) were the most frequent malignancies among males and females, respectively.

Table IV shows the distribution of chronic diseases other than CRC and DM2 among the four patient groups. Diabetic patients belonging to Groups 1 and 3 had a significantly higher proportion of cardiovascular diseases and genitourinary system diseases, namely chronic kidney disease, than nondiabetic patients (87 vs. $56 \%, \mathrm{P}<0.0001$ and 13 vs. $4 \%$, $\mathrm{P}<0.0001$, respectively). Moreover, a significantly higher proportion of respiratory system diseases was found among patients belonging to Group 1 compared with those belonging to Groups $3(\mathrm{P}=0.007)$ and $4(\mathrm{P}=0.002)$.
Cox proportional-hazards regression analysis (Table V) showed that factors resulted in a higher hazard and therefore a shorter survival time controlling for the other factors were CRC stage [hazard ratio $(\mathrm{HR})=1.98$, 95\% $\mathrm{CI}=1.67-2.34, \mathrm{P}<0.0001]$, admission plasma HDL cholesterol lower than $40 \mathrm{mg} / \mathrm{dl}(\mathrm{HR}=1.41,95 \%$ $\mathrm{CI}=1.02-1.95, \mathrm{P}=0.04)$, patient group $(\mathrm{HR}=1.21,95 \%$ $\mathrm{CI}=1.03-1.44, \mathrm{P}=0.02)$ and age at CRC diagnosis $(\mathrm{HR}=1.04,95 \% \mathrm{CI}=1.02-1.05, \mathrm{P}<0.0001)$. However, after testing the proportional hazard assumption, i.e. the null hypothesis of a zero slope in the regression, the assumption held for a model with covariates CRC stage and patient group $\left(\chi^{2}=0.79\right.$, degrees of freedom $\left.=2, P=0.7\right)$. Gompertz and 
Table V. Cox proportional-hazards regression analysis of possible factors affecting mortality from CRC among the 671 study participants.

\begin{tabular}{|c|c|c|c|}
\hline Factors & Hazard ratio & $95 \% \mathrm{CI}$ & P-value \\
\hline CRC stage & 1.98 & $1.67-2.34$ & $<0.0001$ \\
\hline Stage II & 1.24 & 0.79-1.94 & 0.4 \\
\hline Stage III & 2.70 & $1.81-4.04$ & $<0.0001$ \\
\hline Stage IV & 6.94 & $4.14-11.63$ & $<0.0001$ \\
\hline Number of comorbidities & 1.94 & $0.58-6.51$ & 0.3 \\
\hline Local recurrence of $\mathrm{CRC}(0=\mathrm{no}, 1=\mathrm{yes})$ & 1.49 & $0.99-2.23$ & 0.06 \\
\hline Sex $(1=$ male, $2=$ female $)$ & 1.22 & $0.91-1.63$ & 0.2 \\
\hline Patient group ${ }^{\mathrm{a}}$ & 1.21 & $1.03-1.44$ & 0.02 \\
\hline Group 2 & 3.12 & $1.22-8.00$ & 0.02 \\
\hline Group 3 & 3.83 & $1.58-9.29$ & 0.003 \\
\hline Group 4 & 3.37 & $1.44-7.89$ & 0.005 \\
\hline CRC subsite $^{\mathrm{b}}(1=$ proximal, $2=$ distal $)$ & 1.05 & $0.79-1.39$ & 0.8 \\
\hline Age at CRC diagnosis (years) & 1.04 & $1.02-1.05$ & $<0.0001$ \\
\hline CRC-directed therapy ${ }^{\mathrm{c}}$ & 1.03 & $0.88-1.21$ & 0.7 \\
\hline Admission plasma glucose $(\mathrm{mg} / \mathrm{dl})$ & 1.01 & $0.99-1.02$ & 0.1 \\
\hline$\geq 100$ & 1.00 & $0.72-1.39$ & 1.0 \\
\hline Admission plasma total cholesterol (mg/dl) & 1.00 & $0.99-1.00$ & 0.6 \\
\hline $200-239$ & 0.76 & $0.51-1.12$ & 0.2 \\
\hline$\geq 240$ & 0.79 & $0.49-1.26$ & 0.3 \\
\hline Admission plasma triglycerides $(\mathrm{mg} / \mathrm{dl})$ & 1.00 & $0.99-1.00$ & 0.7 \\
\hline 150-199 & 1.07 & $0.64-1.79$ & 0.8 \\
\hline$\geq 200$ & 0.80 & $0.43-1.51$ & 0.5 \\
\hline Admission plasma HDL cholesterol (mg/dl) & 0.98 & $0.97-0.99$ & 0.005 \\
\hline$<40$ & 1.41 & $1.02-1.95$ & 0.04 \\
\hline Comorbidity $(0=$ no, $1=$ yes $)$ & 0.96 & $0.50-1.85$ & 0.9 \\
\hline Diseases of the genitourinary system $(0=\mathrm{no}, 1=\mathrm{yes})$ & 0.96 & $0.30-3.05$ & 0.9 \\
\hline Endocrine, nutritional and metabolic disease other than type 2 diabetes mellitus $(0=$ no, $1=$ yes $)$ & 0.67 & $0.21-2.12$ & 0.5 \\
\hline Invasive malignant neoplasms other than $\mathrm{CRC}(0=\mathrm{no}, 1=\mathrm{yes})$ & 0.61 & $0.18-2.02$ & 0.4 \\
\hline Diseases of the digestive system $(0=$ no, $1=y e s)$ & 0.60 & $0.16-2.23$ & 0.4 \\
\hline Diseases of the circulatory system $(0=$ no, $1=y e s)$ & 0.57 & $0.17-1.98$ & 0.4 \\
\hline Diseases of the blood and disorders involving the immune mechanism ( $0=$ no, $1=y e s)$ & 0.47 & $0.11-2.06$ & 0.3 \\
\hline Diseases of the respiratory system $(0=\mathrm{no}, 1=\mathrm{yes})$ & 0.44 & $0.13-1.51$ & 0.2 \\
\hline Diseases of the nervous system $(0=$ no, $1=$ yes $)$ & 0.43 & $0.09-2.05$ & 0.3 \\
\hline Mental and behavioural disorders $(0=$ no, $1=y e s)$ & 0.43 & $0.08-2.25$ & 0.3 \\
\hline Diseases of the musculoskeletal system and connective tissue $(0=$ no, $1=y e s)$ & 0.24 & $0.02-2.52$ & 0.2 \\
\hline
\end{tabular}

a'DM2: Yes, metformin: Yes, ASA: Yes. Group 2: DM2: No, metformin: No, ASA: Yes. Group 3: DM2: Yes, metformin: Yes, ASA: No. Group 4: DM2: No, metformin: No, ASA: No. bProximal: caecum, ascending colon, hepatic flexure, transverse colon, splenic flexure. Distal: descending colon, sigmoid colon, rectosigmoid junction, rectum. ${ }^{\mathrm{c}} 1=$ surgery, $2=$ surgery and radiotherapy, 3 =surgery and chemotherapy, $4=$ surgery, radiotherapy and chemotherapy. CRC, colorectal adenocarcinoma; DM2, type 2 diabetes mellitus; ASA, acetylsalicylic acid.

log-logistic analyses produced results similar to those reported in Table V.

Five-year CRC-specific and relative survival probabilities stratified by TNM stages and patient groups are shown in Table VI. Cancer-specific survival for stage III CRC was significantly higher in the 18 diabetic patients treated with metformin and ASA (Group 1) than in the 43 diabetic patients treated with metformin but not ASA (Group 3) $(\mathrm{P}=0.008)$, and in the 150 nondiabetic patients not taking ASA (Group 4) $(P=0.03)$. Patients belonging to Group 1 with stage III CRC showed a five-year relative survival 3.5-fold higher $(95 \%$ $\mathrm{CI}=1.4-8.3, \mathrm{P}=0.003$ ) than those belonging to Group 3. On the other hand, the ratio of relative survivals between Group 2 and Group 4 patients with stage III CRC was 1.0 (95\% CI=0.5-1.9, $\mathrm{P}=0.8$ ). To a lesser extent, five-year cancer-specific and relative survivals for stage II CRC were better in DM2 patients on metformin and aspirin therapy compared with Groups 2, 3 and 4. However, survival was similar across the four Groups for stages I and IV. No statistically significant differences in five-year CRC-specific and relative survival probabilities between males and females belonging to the same Groups were found across the four TNM stages.

For each TNM stage and for each patient group, CRC-specific survival curves adjusted for sex and age at diagnosis are shown in Fig. 1. It was possible to draw survival curves for TNM substages IIA and IIIB only (Fig. 2) because of the small number of patients classified in the other substages (Table I). Survival for stage III CRC was significantly higher among patients belonging to Group 1 than among those belonging to Group $2(\mathrm{P}=0.04)$, Group $3(\mathrm{P}=0.004)$ and Group 4 ( $\mathrm{P}=0.01)$. The same was true for stage IIIB (Fig. 2). A not statistically significant higher survival for stages II (Fig. 1) and IIA (Fig. 2) was shown by Group 1 patients compared with those of the other three groups. 


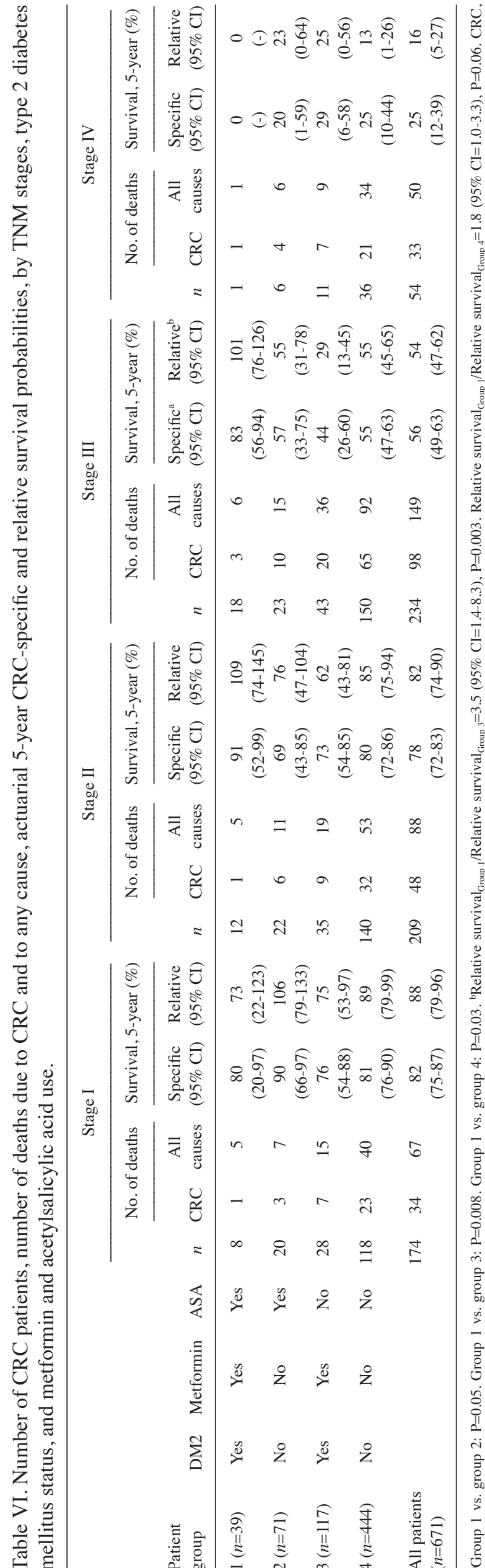

\section{Discussion}

We carried out an observational study on colorectal cancer patients diagnosed between 2004 and 2007 in the Italian province of Trieste. Information on the duration of DM2 and on treatment with antidiabetic drugs and ASA, and on body mass index (BMI) was limited (for BMI it was available only in $10 \%$ of patients). This missing information is, admittedly, a weak point in our study since those data would have improved it. Nonetheless, in the limited number of cases where body mass index was available, a similar distribution of this index was observed between diabetic and nondiabetic patients $(\mathrm{P}=0.3)$ (data not shown) in agreement with Rosato et al (19). Our group of diabetic patients was homogeneous because only patients treated with metformin were enrolled in the study, given that the aim of the study was not to compare the efficacy of metformin with other treatments for DM2.

No statistically significant difference in the proportion of diabetic and nondiabetic patients was found across the four TNM stages for CRC in agreement with Siddiqui et al (20) who reported no differences in stage at presentation in patients with a well-controlled DM2 and nondiabetic controls.

A positive association between DM2 and proximal colon cancer had already been observed, albeit not homogenously, in several studies $(19,21,22)$, but in our study we were not able to confirm this in our study. The distribution of colon subsites was comparable in CRC patients with and without DM2. A possible explanation could be the selection criterion of DM2 patients because only those treated with metformin were included.

Increased plasma triglycerides and reduced HDL cholesterol are the main quantitative lipid abnormalities in diabetic dyslipidemia (23). Diabetic patients who take metformin are patients with more severe diabetes who need pharmacological therapy. In patients with insulin-resistant diabetes treated with metformin, there is the so-called atherogenic dyslipidemia, characterized by fasting hypertriglyceridemia, which is usually associated with low levels of HDL cholesterol and high levels of small and dense LDL particles (24). In our study, the values of total and HDL cholesterol was higher in patients without DM2 taking ASA, while glucose and triglycerides were higher in DM2 patients not on ASA treatment. This is a possible consequence of ASA intake, which lowers plasma triglycerides (25) and suppresses the abnormal lipid metabolism (26). Higher levels of HDL cholesterol in nondiabetic patients taking ASA can also be related to the fact that diabetic patients have significantly lower levels of HDL than nondiabetic patients (27).

In the present study cardiovascular diseases, malignancies other than CRC and chronic kidney diseases are the most frequent comorbidities in DM2 patients in agreement with other studies $(28,29)$. Diabetes mellitus is, indeed, a major risk factor for cardiovascular diseases, whose prevalence is twice as high in males and even four times more frequent in females (30).

Among the variables affecting survival, CRC stage and plasma HDL cholesterol lower than $40 \mathrm{mg} / \mathrm{dl}$ had a negative effect on survival. Higher stage at diagnosis is, of course, related to a worse prognosis. As regards HDL cholesterol, our data are indirectly supported by Notanicola and colleagues, who reported that the presence of metastases in CRC patients 

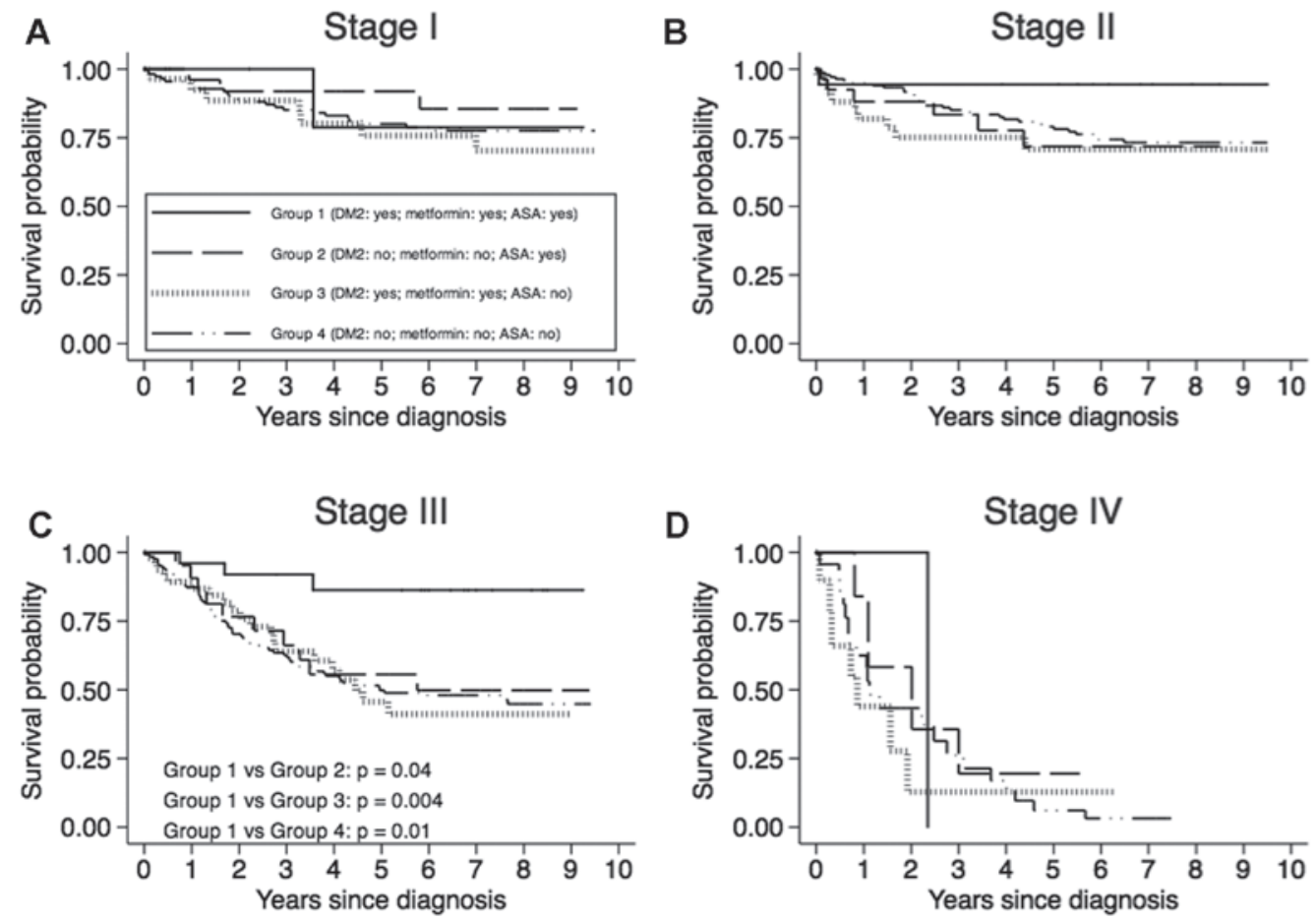

Figure 1. Colorectal adenocarcinoma-specific survival curves adjusted for sex and age at diagnosis, by TNM stage and patient group. (A) Stage I, (B) Stage II, (C) Stage III and (D) Stage IV patients.
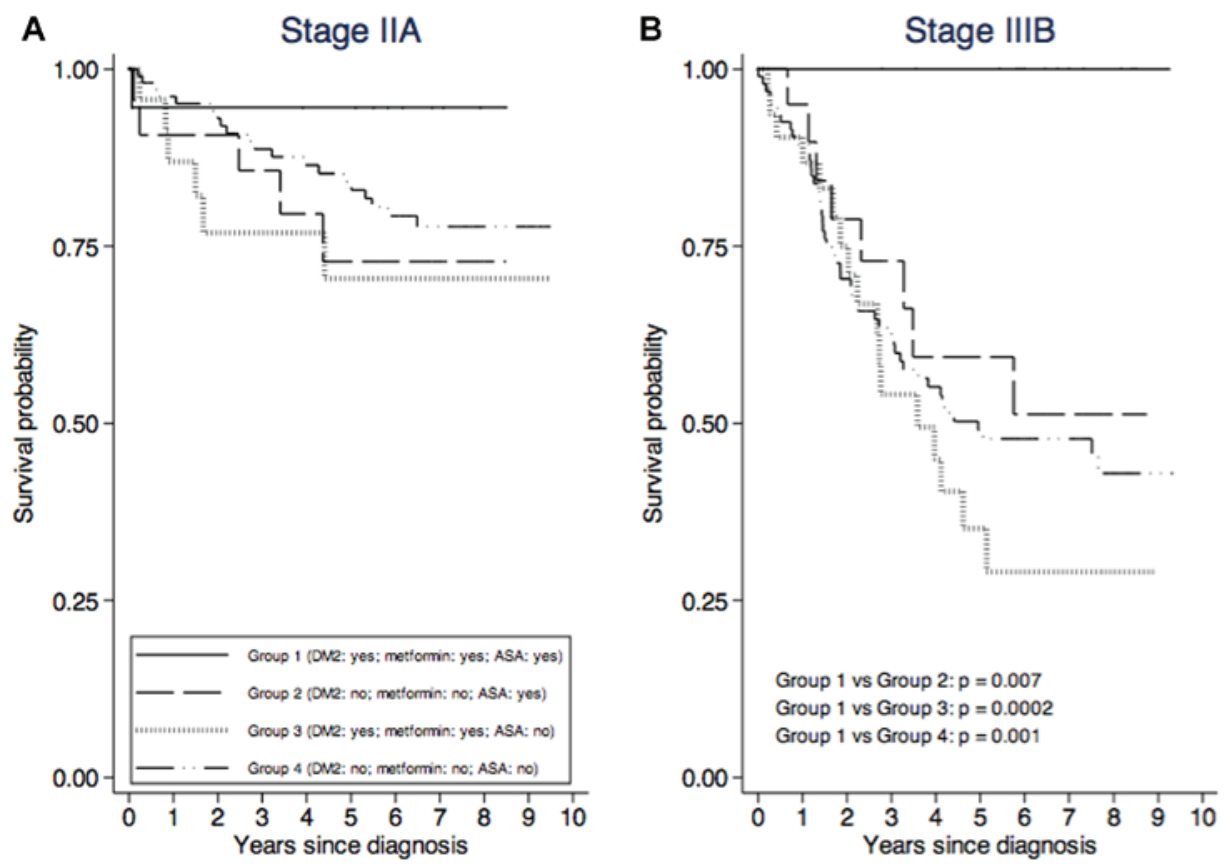

Figure 2. Colorectal adenocarcinoma-specific survival curves adjusted for sex and age at diagnosis, by patients' group and TNM (A) IIA substage and (B) IIIB substage.

was associated to higher levels of LDL cholesterol over HDL cholesterol ratio, irrespective of sex and BMI (31). Additionally, the relationship between Serum Amyloid A and HDL particles can explain the inverse relationship between HDL cholesterol levels and cancer (32).

Daily ASA intake has been shown to reduce incidence and mortality from CRC $(33,34)$. In the present study, the protective effect of ASA in both diabetic and nondiabetic patients is suggested by the older median age at CRC diagnosis of patients taking ASA. However, in agreement with the results of Din et al (33), no influence of ASA alone on cancer-specific and relative survival was observed.

Diabetic patients treated with metformin showed a lower incidence of CRC (35-37) and mortality from CRC (38-40). In the present study, diabetic patients taking ASA and metformin have both higher five-year cancer-specific and relative survival 
for stage II and III CRC compared with diabetic patients not taking ASA and to nondiabetic patients with or without ASA intake. These results differ from those obtained by Mei et al (38), Du et al (39) and Ramjeesingh et al (40) who showed the protective effect of metformin on CRC patient mortality. On the other hand, Zanders and colleagues (41) did not find any survival improvement in CRC patients taking metformin or ASA.

Our results indirectly support the hypothesis of a possible interaction between ASA and metformin in anticancer activity, even though those drugs are not labelled for cancer therapy. O'Brien et al (7) showed that salicylate and metformin reduce synergistically or additively the clonogenic survival of prostate and lung cancer cells by inhibiting de novo lipogenesis. Furthermore, the combination of metformin and 5-ASA, which displays a mechanism similar to ASA in inhibiting COX-2 enzyme, has recently been shown to increase cell death in CRC cell lines (42). Nonetheless, we cannot exclude the possibility that metformin alone or in combination with ASA could enhance the chemotherapeutical activity of 5-fluorouracil (5-FU), since the major benefit of metformin and ASA was observed in stage III CRC patients, who underwent adjuvant 5-FU chemotherapy. A synergistic effect of metformin in combination with 5-FU on CRC stem cell proliferation has already been hypothesized (43).

The findings reported are promising but, like all descriptive epidemiological studies, our study was exploratory and aimed at generating hypotheses. Therefore, randomized controlled trials investigating the combined effect of metformin and ASA on CRC patient survival are needed to confirm or refute our findings.

\section{Acknowledgements}

We wish to thank Dr C.J. Garwood for his language editing work on the manuscript.

\section{Competing interests}

The authors declare that they have no competing interests.

\section{References}

1. Binefa G, Rodríguez-Moranta F, Teule A and Medina-Hayas M: Colorectal cancer: From prevention to personalized medicine. World J Gastroenterol 20: 6786-6808, 2014.

2. Guariguata L, Whiting DR, Hambleton I, Beagley J, Linnenkamp U and Shaw JE: Global estimates of diabetes prevalence for 2013 and projections for 2035. Diabetes Res Clin Pract 103: 137-149, 2014.

3. Renehan AG, Yeh HC, Johnson JA, Wild SH, Gale EA and Møller H; Diabetes and cancer research consortium: Diabetes and cancer (2): Evaluating the impact of diabetes on mortality in patients with cancer. Diabetologia 55: 1619-1632, 2012.

4. Johnson JA, Carstensen B, Witte D, Bowker SL, Lipscombe L and Renehan AG; Diabetes and cancer research consortium: Diabetes and cancer: Evaluating the temporal relationship between type 2 diabetes and cancer incidence. Diabetologia 55: 1607-1618, 2012.

5. Park HK: Metformin and cancer in type 2 diabetes. Diabetes Metab J 37: 113-116, 2013.

6. Din FV, Valanciute A, Houde VP, Zibrova D, Green KA, Sakamoto K, Alessi DR and Dunlop MG: Aspirin inhibits mTOR signaling, activates AMP-activated protein kinase, and induces autophagy in colorectal cancer cells. Gastroenterology 142: $1504-1515$ e3, 2012
7. O'Brien AJ, Villani LA, Broadfield LA, Houde VP, Galic S, Blandino G, Kemp BE, Tsakiridis T, Muti P and Steinberg GR: Salicylate activates AMPK and synergizes with metformin to reduce the survival of prostate and lung cancer cells ex vivo through inhibition of de novo lipogenesis. Biochem J 469: 177-187, 2015.

8. Edge S, Byrd DR, Compton CC, Fritz AG, Greene FL and Trotti A: AJCC Cancer Staging Manual. Springer-Verlag, New York, 2010

9. American Diabetes Association: Diagnosis and classification of diabetes mellitus. Diabetes Care 37 (Suppl 1): S81-S90, 2014.

10. Word Health Organization: ICD-10 International statistical classification of diseases and related health problems. World Health Organization, Geneva, 2011.

11. Armitage $P$ and Berry G: Statistical methods in medical research. 2nd edition. Oxford, Boston, Blackwell Scientific, Chicago, III, Distributors, USA, Year Book Medical Publishers, England, 1987.

12. Kalbfleisch JD and Prentice RL: The statistical analysis of failure time data. John Wiley, New York, 1980.

13. Grambsch PM and Therneau TM: Proportional hazards tests and diagnostics based on weighted residuals. Biometrika 81: 515-526, 1994.

14. Estève J, Benhamou E and Raymond L: Statistical methods in cancer research. Volume IV. Descriptive epidemiology. IARC Sci Publ 1994: 302, 1994.

15. Ederer F, Axtell LM and Cutler SJ: The relative survival rate: A statistical methodology. Natl Cancer Inst Monogr 6: 101-121, 1961.

16. Patruno V, Venturi M and Roberto S: Demografia in cifre-Tavole di Mortalità. Available from ISTAT. http://www.demo.ist at.it/tvm2016.

17. Breslow NE and Day NE: Statistical methods in cancer research. Volume II-The design and analysis of cohort studies. IARC Sci Publ: 1-406, 1987.

18. Cuzick J: A Wilcoxon-type test for trend. Stat Med 4: 87-90, 1985.

19. Rosato V, Tavani A, Gracia-Lavedan E, Guinó E, Castaño-Vinyals G, Villanueva CM, Kogevinas M, Polesel J, Serraino D, Pisa FE, et al: Type 2 diabetes, antidiabetic medications and colorectal cancer risk: Two case-control studies from italy and spain. Front Oncol 6: 210, 2016.

20. Siddiqui AA, Spechler SJ, Huerta S, Dredar S, Little BB and Cryer B: Elevated $\mathrm{HbA} 1 \mathrm{c}$ is an independent predictor of aggressive clinical behavior in patients with colorectal cancer: A case-control study. Dig Dis Sci 53: 2486-2494, 2008.

21. Campbell PT: The role of diabetes and diabetes treatments in colorectal cancer mortality, incidence and survival. Curr Nutr Rep 2: 37-47, 2013.

22. Peeters PJ, Bazelier MT, Leufkens HG, de Vries F and De Bruin ML: The risk of colorectal cancer in patients with type 2 diabetes: Associations with treatment stage and obesity. Diabetes Care 38: 495-502, 2015.

23. Vergès B: Pathophysiology of diabetic dyslipidaemia: Where are we? Diabetologia 58: 886-899, 2015.

24. Sirtori CR, Calabresi L, Pisciotta L, Cattin L, Pauciullo P, Montagnani M, Manzato E, Bittolo Bon G and Fellin R: Effect of statins on LDL particle size in patients with familial combined hyperlipidemia: A comparison between atorvastatin and pravastatin. Nutr Metab Cardiovasc Dis 15: 47-55, 2005.

25. van Diepen JA, Vroegrijk IO, Berbée JF, Shoelson SE, Romijn JA, Havekes LM, Rensen PC and Voshol PJ: Aspirin reduces hypertriglyceridemia by lowering VLDL-triglyceride production in mice fed a high-fat diet. Am J Physiol Endocrinol Metab 301: E1099-E1107, 2011.

26. Yang G, Wang Y,Feng J,Liu Y, Wang T,Zhao M, YeL and Zhang X: Aspirin suppresses the abnormal lipid metabolism in liver cancer cells via disrupting an NFKB-ACSL1 signaling. Biochem Biophys Res Commun 486: 827-832, 2017.

27. Eliasson B, Gudbjörnsdottir S, Zethelius B, Eeg-Olofsson K and Cederholm J; National diabetes register (NDR): LDL-cholesterol versus non-HDL-to-HDL-cholesterol ratio and risk for coronary heart disease in type 2 diabetes. Eur J Prev Cardiol 21: 1420-1428, 2014.

28. Middleton RJ, Foley RN, Hegarty J, Cheung CM, McElduff P, Gibson JM, Kalra PA, O'Donoghue DJ and New JP: The unrecognized prevalence of chronic kidney disease in diabetes. Nephrol Dial Transplant 21: 88-92, 2006. 
29. Dörhöfer L, Lammert A, Krane V, Gorski M, Banas B, Wanner C, Krämer BK, Heid IM and Böger CA; DIACORE Study Group: Study design of DIACORE (DIAbetes COhoRtE) a cohort study of patients with diabetes mellitus type 2. BMC Med Genet 14: $25,2013$.

30. Casanova F, Adingupu DD, Adams F, Gooding KM, Looker HC, Aizawa K, Dove F, Elyas S, Belch JJF, Gates PE, et al: The impact of cardiovascular co-morbidities and duration of diabetes on the association between microvascular function and glycaemic control. Cardiovasc Diabetol 16: 114, 2017.

31. Notarnicola M, Altomare DF, Correale M, Ruggieri E, D'Attoma B, Mastrosimini A, Guerra V and Caruso MG: Serum lipid profile in colorectal cancer patients with and without synchronous distant metastases. Oncology 68: 371-374, 2005.

32. Gomaraschi M, Ossoli A, Favari E, Adorni MP, Sinagra G, Cattin L, Veglia F, Bernini F, Franceschini G and Calabresi L: Inflammation impairs eNOS activation by HDL in patients with acute coronary syndrome. Cardiovasc Res 100: 36-43, 2013.

33. Din FV, Theodoratou E, Farrington SM, Tenesa A, Barnetson RA, Cetnarskyj R, Stark L, Porteous ME, Campbell $\mathrm{H}$ and Dunlop MG: Effect of aspirin and NSAIDs on risk and survival from colorectal cancer. Gut 59: 1670-1679, 2010.

34. Sehdev A and O'Neil BH: The role of aspirin, vitamin D, Exercise, diet, statins and metformin in the prevention and treatment of colorectal cancer. Curr Treat Options Oncol 16: 43 2015.

35. Zhang ZJ, Zheng ZJ, Kan H, Song Y, Cui W, Zhao G and Kip KE: Reduced risk of colorectal cancer with metformin therapy in patients with type 2 diabetes: A meta-analysis. Diabetes Care 34: 2323-2328, 2011

36. Liu F, Yan L, Wang Z, Lu Y, Chu Y, Li X, Liu Y, Rui D, Nie S and Xiang H: Metformin therapy and risk of colorectal adenomas and colorectal cancer in type 2 diabetes mellitus patients: A systematic review and meta-analysis. Oncotarget 8: 16017-16026, 2017.

37. Nie Z, Zhu H and Gu M: Reduced colorectal cancer incidence in type 2 diabetic patients treated with metformin: A meta-analysis. Pharm Biol 54: 2636-2642, 2016.

38. Mei ZB, Zhang ZJ, Liu CY, Liu Y, Cui A, Liang ZL, Wang GH and Cui L: Survival benefits of metformin for colorectal cancer patients with diabetes: A systematic review and meta-analysis. PLoS One 9: e91818, 2014.
39. Du L, Wang M, Kang Y, Li B, Guo M, Cheng Z and Bi C: Prognostic role of metformin intake in diabetic patients with colorectal cancer: An updated qualitative evidence of cohort studies. Oncotarget 8: 26448-26459, 2017.

40. Ramjeesingh R, Orr C, Bricks CS, Hopman WM and Hammad N: A retrospective study on the role of diabetes and metformin in colorectal cancer disease survival. Curr Oncol 23: e116-e122, 2016.

41. Zanders MM, van Herk-Sukel MP, Vissers PA, Herings RM, Haak HR and van de Poll-Franse LV: Are metformin, statin and aspirin use still associated with overall mortality among colorectal cancer patients with diabetes if adjusted for one another? Br J Cancer 113: 403-410, 2015.

42. Saber MM, Galal MA, Ain-Shoka AA and Shouman SA: Combination of metformin and 5-aminosalicylic acid cooperates to decrease proliferation and induce apoptosis in colorectal cancer cell lines. BMC Cancer 16: 126, 2016.

43. Zhang Y, Guan M, Zheng Z, Zhang Q, Gao F and Xue Y: Effects of metformin on CD133+ colorectal cancer cells in diabetic patients. PLoS One 8: e81264, 2013. 